NOTA

\title{
Centenario de la Organización Panamericana de la Salud
}

\author{
Eduardo Alvarez \\ Representante OPS/OMS en Colombia
}

\begin{abstract}
La Organización Panamericana de la Salud celebra 100 años de cooperación internacional en salud. En todos los países miembros se realizarán actos conmemorativos.
\end{abstract}

El 2 de diciembre de 1902, los representantes de 11 países de las Américas se reunieron en Washington para poder consolidar un frente unido contra la propagación de las epidemias y las enfermedades infectocontagiosas; se creó, entonces, la Oficina Sanitaria Internacional, que en 1923 cambió su nombre a Oficina Sanitaria Panamericana y que en 1958, después de convertirse en Oficina Regional de la Organización Mundial de la Salud, cambió su nombre a Organización Panamericana de la Salud, hoy en día con 35 países miembros y 4 países observadores, constituyendo el organismo internacional más antiguo del mundo de ininterrumpida dedicación a la cooperación técnica en salud pública.

Con la celebración este año del centésimo aniversario de la Organización Panamericana de la Salud, se conmemora el compromiso ineludible de los países que firmaron su constitución y cien años de cooperación técnica en el desarrollo de la salud pública en la Región de las Américas.

La historia de la OPS ha seguido un camino paralelo a los profundos cambios sociales, políticos y económicos que han marcado la evolución de sus países miembro y, por ello, el ámbito de su acción, inicialmente limitado al control de las enfermedades infectocontagiosas, se ha ampliado para responder a las necesidades

Correspondencia:

Carrera 7 No. 74-21, piso 9º Bogotá, D.C., Colombia.

Recibido: 09/05/02; aceptado: 16/05/02 cambiantes de la población, pero siempre buscando mejores condiciones de vida y de salud.

Para definir el marco de acción institucional para períodos cuadrienales, la Organización realiza un ejercicio colectivo de planificación estratégica que se condensa en un documento llamado de Orientaciones estratégicas y programáticas que es aprobado por la Conferencia Sanitaria Panamericana, la cual congrega a los Ministros de Salud de los países miembros y a los Cuerpos Directivos de la Organización. Este documento marca el rumbo de las líneas de trabajo en los países con un enfoque panamericano, que alienta la solidaridad y la cooperación técnica entre los países para un trabajo en pro de metas comunes. Así, a través del tiempo se han creado estrategias diversas como el Plan Decenal de Salud Pública de 1961, el Plan Decenal de Salud para las Américas de 1980 y la estrategia de Salud para Todos en el año 2000.

Es de anotar, sin embargo, que la definición de los planes de trabajo en cada país toma en cuenta las necesidades prioritarias en cada uno $\mathrm{y}$, a través de procesos de concertación con las autoridades nacionales, se definen los programas que permitan la mejor utilización de los recursos y la mayor pertinencia en la cooperación, lo cual implica que en algunos países se haga énfasis especial en algunos programas o se implementen otros más específicos como es, por ejemplo, el caso de los países que viven graves situaciones de conflicto interno y en los que los problemas de secuelas de la violencia se convierten en verdaderos problemas de salud pública. En Colombia, actualmente la Organización pone énfasis especial en tres líneas estratégicas de acción como son el fortalecimiento de la gestión y administración de programas y servicios; la 
recopilación, el uso y el análisis de la información, y la atención a poblaciones más vulnerables.

Para llevar a cabo sus actividades de cooperación técnica, la OPS adopta seis enfoques funcionales: movilización de recursos de toda índole, difusión de información, capacitación, desarrollo de normas, planes y políticas, promoción de la investigación y consultoría técnica directa.

Un claro ejemplo de cómo se combinan los enfoques funcionales es el Programa Ampliado de Inmunizaciones en el cual la OPS colabora con los países para proporcionar servicios de inmunización y tratamiento para todas las enfermedades prevenibles por vacunación. Esa acción ha logrado que los países de América Latina y el Caribe se unieran hace más de 20 años para comprar vacunas mediante un fondo rotatorio y ha producido beneficios tangibles como la erradicación de la viruela y la poliomielitis, estando cerca de alcanzar la meta de eliminar el sarampión en este continente.

La Representación de la OPS en Colombia se estableció formalmente en 1951 y el 7 de diciembre de 1954 se firmó el convenio básico que norma las relaciones entre el gobierno colombiano y la Organización y, desde entonces ha prestado cooperación técnica de manera ininterrumpida en numerosos campos.

Este año, para conmemorar el centenario de la institución, se han programado numerosas celebraciones que pretenden resaltar los logros alcanzados en el desarrollo de la salud pública, los cuales han sido posibles por el compromiso de la Organización y el apoyo y trabajo permanentes de las autoridades de cada uno de los países miembros. Se pretende, igualmente, propiciar espacios de discusión y reflexión acerca de la importancia de la salud como pilar del desarrollo social y de la salud pública como un compromiso colectivo que requiere de trabajo intersectorial y de la definición de políticas de estado y no solamente de trabajo sectorial. En ese sentido, la Representación en Colombia está invitando a la comunidad en general a unirse a las celebraciones y al proceso reflexivo, de tal manera que podamos fortalecer ese trabajo colectivo en pro de un mayor bienestar y de un acceso más equitativo a la salud para toda la comunidad. 